\title{
Managing the development of complex socio- economic systems in the digital economy paradigm
}

\author{
Natalia Gorbunova ${ }^{1 *}$, Rena Timirgaleeva ${ }^{1}$, and Alina Khrulyova $^{1}$ \\ ${ }^{1}$ V. I. Vernadsky Crimean Federal University, 298600, Simferopol, Russian Federation
}

\begin{abstract}
The article presents the integrated approach to managing the development of complex socio-economic systems based on the digital transformation of business through the transition from document-centricity to data-centricity, reengineering of the organizational structure in the direction of its design on the principle of forming cross-teams, whose activities are aimed at creating effective value chains of a digital product for the consumer. The article also provides an analysis of research on the problem of the socio-economic systems development and their evolution. The knowledge modeling toolkit based on model technologies Data Science, Business Intelligence, Big Data, Data Mining and, in particular, Deep Learning, was used to assess the level of the socio-economic system and manage its potential development.
\end{abstract}

\section{Introduction}

The study relevance is determined by the list of instructions of the President of the Russian Federation, as well as the Strategy for the scientific and technological development of the Russian Federation. The socio-economic system, regardless of the form of ownership, size, industry, has a certain potential. The economic development of the country as a whole, the well-being of its citizens, and the country's worthy place in the world community depend on its size and use. The solution of the strategic tasks of the development of complex socioeconomic systems requires the search for effective models and mechanisms of management that are adequate to modern economic conditions. More and more, the process of interaction between the state and economic entities of different levels is carried out through digital technologies.

The transformation of socio-economic relations in the digital economy makes it necessary to form a mechanism for the effective use and development of the potential of complex socio-economic systems of different levels. This mechanism should combine a system of levers and incentives that can ensure the effective use of investment, innovation, natural resource and labor potentials, each of which is characterized by a certain quantitative and qualitative state of the corresponding types of economic resources.

\footnotetext{
* Corresponding author: natalya-gor2008@yandex.ru
} 
A consistent restructuring of the system for managing the potential of complex socioeconomic systems within the framework of digital transformation will bring the national economy to a new level of efficiency and ensure the transition to a shared consumption economy, which fundamentally changes the structure of the global economic system, expands consumer opportunities, and also affects the structure of industries and the role of states. in this system.

In this regard, the relevance of the effective system formation for assessing the potential of a complex socio-economic system, and determining the influence of environmental factors on it, increases. Taking into account the foregoing, it becomes urgent to develop the conceptual provisions of the economic and mathematical tools for managing the development of the potential of complex socio-economic systems based on the modern system-synergetic paradigm, research and use of self-organization mechanisms for the analysis, synthesis, forecasting and management of complex dynamic socio-economic systems in the digital economy paradigm.

Scientists and researchers at different stages of the managerial thought development tried to study the features of the functioning of socio-economic systems, determine the reserves of their development, and create a system for assessing their potential. At the same time, consideration of the socio-economic system management is often carried out through the formation of opportunities for its potential development.

The study of the development problems of socio-economic systems and their evolution are devoted to the works of a number of foreign scientists: M. Weber, J.K. Galbraith, J.M. Keynes, M. Clark, K. Marx, J. Schumpeter. In Russia, the most significant in the field of research of the socio-economic systems development are the studies of the following scientists: L. Abalkin, D. Berg, V. Burdakov, S. Glazyev, T. Ignatova, G. Ovcharenko, V. Ovchinnikov, A. Panarin, V. Popkov, R. Nureev and others.

One of the most used systems for assessing the potential of an organization is the balanced scorecard. The possibilities of this approach were studied in the works of J. Weber, W. Shaffer, A. Korobkov, M. Gershun, N. G. Olve, J. Roy, M. Vetter. In national economic science, the most thoroughly assessing the potential were: D. Stepanov, E. Popov, Yu. Nefedieva, A. Gorsky, I. Abramova, I. Averchev, etc. Despite a significant number of scientific works devoted to the study of potential and the formation of approaches to its assessments, many of them do not have the qualities of adaptability to the conditions of the Russian economy and environmental factors, insufficiently cover the essential characteristics of the organization's potential as a socio-economic system.

National and foreign scientists, in particular V. Apalkova, S. Veretyuk, P. Drucker, S. Kolyadenko, I. Karcheva, B. King, R. Lipsi, L. Lyamin, I. Malik, V. Pilinsky, Y. Pivovarov, K. Skinner, E. Toffler, V. Fishchuk, K. Schwab, etc., have paid much attention to the problem of the digital economy development and the transformation processes taking place in society under the digitalization influence. At the same time, despite numerous scientific studies on the digital economy development, in an environment where digital technologies are becoming more sophisticated and integrated, causing the transformation of society and the global economy, the issues of managing the potential development of complex socio-economic systems in the context of the functioning of the digital economy remain insufficiently studied.

A great contribution to the concept formation of adaptive management in economic and technical systems, analysis of the socio-economic systems adaptation in modern economic conditions was made by such national and foreign scientists-economists as: R. Ackoff, I. Ansoff, M. Albert, M. Mescon , F. Hedowry, G. Mintzberg, B. Milner, I. Markina, T. Burns, T. Davenport, T. Peters, R. Waterman, T. Harutyunyan, A. Gradov, I. Adizes, M. Green, E. Cameron, G. Kleiner, N. Lepa, A. Nalivayko, A. Raevneva and others. The study of the essence of the category "economic potential", the problems of its formation 
and management are reflected in the scientific works of O. Bazhanov, S. Bai, A. Balatsky, Yu. Donets, P. Drucker, N. Krasnokutsky, B. Artemiev, D. Vasilkovsky, L. Koval, E. Lapina, I. Otenko and others.

The methodological basis for the study of the management of economic entities competitive advantages was created by such scientists as: M. Porter, J. Schumpeter, A. Ivanova, J. Lamben, I. Balabanova, E. Poltavskaya, Yu. Ivanov, G. Azov, A. Thompson, V. Tkachenko, G. Fatkhutdinov, I. Otenko, etc. A number of authors in their research and publications emphasize the exceptional importance and necessity of active implementation of the digital economy [1, 2, 3-13, 14]. So, A. Babkin singles out the digital culture development as a key factor in digital transformation in the activities of market entities, and also substantiates the need for technical normalization of the digital economy [1]; $\mathrm{V}$. Varnavsky in his study [2] examines general approaches to assessing the digital technologies impact on the growth of the world economy; T.Hasanov identifies information and communication technologies as the main factor of the digital economy, and also reveals the mechanism of action of a quantum computer and its interaction with the digital economy; for their part, the authors of this publication conduct research related to the construction and optimization of business processes in the digital economy [5, 12]; A. Dobrynin in his study [6] gives a consistent description of actions to realize the benefits of the digital economy through the use of information technology; V. Klochkov describes the effects of digital economy technologies that affect the industrial sector, and also analyzes approaches to their classification and quantification [7]; S. Makrushin in his study [8] examines the impact of new properties of economic goods that are digital in nature, on production and economic relations and social institutions; B. Panshin examines the features and prerequisites for the digital economy development, determines the factors of its significance for economic growth, considers the risks of return on investment in the digital economy formation and proposes measures to reduce them [9]; E. Popov proposes to rely on the concept of econotronics proposed by him for the economic description of social driving forces in modern society at the regional level, which he presents as a separate section of the social sciences on the dynamics of economic institutions development of interaction between factors and society in the digital economy [9]; I. Sudarushkina [11] examines in her study the relationship between the level of digital economy development, as reflected by the Global Connectivity Index, and countries' GDP per capita; G. Chernukhina explores the issues of the information technologies influence introduced into state administrative activities on the system of public relations and the management style [14].

The studies of foreign authors [15-19] are of interest for our research. So, L. Wang and T. Kjellberg [15] propose a new concept of the technological data market (TDMP), which allows you to process data from the production process. The authors note that digital dissemination of data is associated with various risks from hacker attacks, theft or manipulation of data, so the use of effective security methods and mechanisms is the key to the success of TDMP. The scientific objective of this study is to develop a secure concept for the exchange of technological data between market participants, it also discusses the development of new business models based on existing resources that create a new value stream in the industry. Sung T. Kung [16] in his study provides a detailed practical discussion of Industry 4.0 and suggests ways to move to Industry 4.0 in Korea, taking into account political factors. The authors [17] see the uniqueness of Industry 4.0 in providing Internet-connected intelligent systems, including automated factories, organizations, development on demand and "on-time" development, includes the integration of cyberphysical systems (CPS), Internet of Things (IoT), cloud and foggy computing paradigms for the development of smart systems, smart homes and smart cities. 
Considering that Industry 4.0 includes sensory fields, actuators, nebula and cloud processing paradigms, as well as network systems, the authors highlight the existing problems, the main one of which, in their opinion, is the need to process heterogeneous data sources and ensure their security. To solve the problem, the authors propose a threat intelligence scheme that models the dynamic interactions of industry 4.0 components, including physical and network systems. Their proposed threat intelligence technique is based on Markov Models (MHMM) hidden in the beta mix to detect anomalous activity against physical and networked systems. Qian, Feng Zhong, Weimin Du, Wenli [18] presented the main constraints in the operation of petrochemical enterprises, including limitations in decision-making, production activities, efficiency and safety, information integration, etc. The authors argue that this industry should be provided with efficient, environmentally friendly and smart production, modern information technologies should be used throughout the entire process of production optimization, management and marketing, for which the authors propose to focus on smart equipment in production processes, as well as on adaptive intelligent optimization of the production process, operating mode and supply chain management, and also put forward key scientific problems in the field of design: intelligent perception and integration of all process information, including information about production and management; collaborative decision making in the supply chain, industry chain and knowledge-based value chain; joint control and optimization of production processes throughout the enterprise through the interaction between humans and cyber physics; life cycle assessment for safety and environmental monitoring in addition to trace analysis and risk control. P. Markon, F. Zezulka, I. Vesely, Z. Szabo, Z. Roubal, O. Sajdl, E. Gesheidtova, P. Dohnal [19] conducted an analysis of communication protocols for Industry 4.0, revealed general trends that are currently conducted in the field of automation and data exchange in manufacturing technologies, and also proposed an author's concept, which includes Cyber-Physical Systems (CPS), Internet of Things (IoT), Internet of Services (IoS) and cloud computing.

At the same time, despite the fairly broad views of modern researchers on the digital economy problems, a number of issues remain unresolved, among which we note the need for modeling and managing the security of information processes in the digital economy. Despite the high scientific and practical value of the research carried out, most of the available information sources highlight certain problems of developing the potential of complex socio-economic systems. In this regard, a number of unresolved issues remain related to the development of the concept, methods and ways of managing the process of managing the potential development of complex socio-economic systems. Issues related to the formation of a mechanism for managing the potential development of socio-economic systems in the digital economy require special attention.

In order for complex socio-economic systems to be able to respond to the challenges of our time, it is necessary to provide theoretical and methodological support for managing the development of their potential, which, in the context of the digital economy transformation, allows finding those tools and opportunities for influence to obtain constancy and stability in the implementation of the contributing to them tasks that would facilitate their transition to a new development qualitative level. The high degree of relevance, as well as the insufficient development of the managing problem of the potential development of complex socio-economic systems of the digital economy, determined the choice of the topic, goal and objectives of this study.

\section{The purpose of the study}

The purpose of the study is to develop an integrated approach to development managing of complex socio-economic systems based on the digital transformation of business through 
the transition from document-centricity to data-centricity, reengineering the organizational structure towards its design based on the principle of forming cross-teams, whose activities are aimed at creating effective value chains for a digital product for the consumer.

\section{Methodology}

The study is based on a monographic and comparative analysis of existing approaches to managing the development of complex socio-economic systems. Abstract-logical method and historical method were used for descriptive and constructive substantiation of the new economic categories essence. When substantiating the mechanism for managing the development of complex socio-economic systems and determining its components, an integrated approach was used.

To assess the level of the socio-economic system and manage the development of its potential, a knowledge modelling toolkit based on model technologies Data Science, Business Intelligence, Big Data, Data Mining and, in particular, Deep Learning, was used. The above methodological approaches are aimed at integrating analytical tools that are advisable to use in potential developing of complex socio-economic systems in the digital economy.

\section{Results and discussion}

As the study of the problem has shown, in order to solve it, it is necessary, first of all, to change thinking. Digital transformation is inevitable, since the processes taking place in the world are associated not only with the objective appearance and development of new information technologies and systems, but also with the emergence of new business models for their application. This circumstance requires the development of the intellectual and innovative potential of digital economy users. A striking example of complex socioeconomic systems are banks, whose business is moving today from offices and cash registers to the digital space, which is extremely in demand for modern clients. At the same time, customers have more and more new requests and requirements not only for the availability of digital financial (banking) services, but also for their quality. It should be noted that banks are well aware of the situation, and leading banks are already actively involved in the digital transformation of their business models and information architecture. It is the digital transformation of business models that makes it possible to provide clients with financial (banking) services not in bank offices, which cannot work around the clock and without interruptions, but at any time of the day, anywhere, when it is demanded by the client. At the same time, customers can receive a service of any kind - from a bank transfer to receiving a comprehensive service, for example, payment for a purchase, utility services, etc.

Without going into the technical issues of digital transformation of business models and, accordingly, business processes, we note the essence and possibilities of digital transformation in such aspect as the transition from document-centricity to data-centricity, when the main focus is shifting from financial documents to the main archive of digital organization, which represents its data. It is the transition to data-centricity that makes it possible to place the client at the center of banking activity, when the bank has the opportunity not only to provide the client with high-quality, timely service, but also to predict his behavior, as well as to identify and shape his needs and preferences.

At the same time, we note that the successful implementation of this approach leads to the creation of automated chains of operations that are quite easy to program. However, by themselves, they are not of great value to the client, but ensuring that they are carried out 
correctly can be guaranteed through digital transformation, which, ultimately, will increase efficiency and significantly reduce the cost of operations. These are the tasks that the digital economy sets and aims to solve.

At the same time, there are a number of both objective and subjective reasons, the presence of which inhibits digital transformation. First of all, we note that most of the business deals with already existing analog services, the transformation of which into digital is associated with the need to redesign them. And, as you know, alteration can sometimes cost much more than the effect obtained. Therefore, in each individual case, it is necessary to evaluate the economic efficiency or, at least, the feasibility of such a transformation. The ideal approach is when the design of the service itself begins immediately with its digital presentation. At the same time, the projected service should initially have at least the following properties: promptness of provision and ease of receipt. In fact, the digital transformation of a complex socio-economic system should completely eliminate the shortcomings of the existing irrational organizational structure, and, ideally, not improve it, but completely replace it. But this is ideally, but in practice it is not always possible and expedient to carry out such a transformation, since replacing an analog system with a digital one will require much greater costs (resources, finance, labor costs, etc.) than the resulting effect.

One of the options for solving this problem may be the reengineering of the organizational structure in the direction of its design not according to the traditional principle of forming structural divisions, but according to the principle of forming project or cross-teams that can combine business, IT sector, marketing, which will allow to form effective chains of formation and delivery of digital product value for the consumer. The introduction of such structures will speed up the production cycle, reduce the time to market a product, and reduce logistics costs. In addition, various socio-economic systems must, as before, adapt to changes in the external environment, which, in the digital economy, should be done by infusing into the so-called ecosystems [20], which are dynamic and jointly developing complex socio-economic systems, including various subjects who, on the one hand, create, and, on the other, receive new advantages for themselves from such interaction, including in the competitive struggle. The structure of such ecosystems presupposes the obligatory presence of customers (consumers) in them, which, in fact, become a part, an integral element of this ecosystem, which allows them to freely exchange information, providing subjects of a business with information about the preferences and needs of customers, the ability to constantly "see" the client with all his problems and direct the efforts of his business to create new functionality for the consumer.

The basis for the creation of complex socio-economic ecosystems is, according to experts [21], a digital platform (it should be one, and there can be as many applications as you like, depending on the degree of complexity and functionality of the system), which provides for a variety of models of interaction of the elements (components) of the ecosystem where third-party services or applications are expected to participate in the customer's value chain.

The presence of one digital platform as part of the ecosystem is due to the fact that it has a high cost, which can be within the reach of consolidated participants who unite on the basis of legal independence, which is important when deciding on entry into the ecosystem by the entities. Also, with this approach to the ecosystem formation, each of the subjects can prepare their own application, which can compete with the applications of other subjects of the system, which will allow adopting the most competitive, and therefore the best application. Another important condition for the effective ecosystem formation on a common basis (digital platform) is openness, which allows accepting new participants and, accordingly, reducing costs by attracting their resources. Thus, we again come to the thesis 
that the digital platform is not so much a technology as a change in thinking under the influence of the digital economy challenges.

\section{Conclusion}

The purpose of this article is to develop an integrated approach to managing the development of complex socio-economic systems based on digital business transformation, as well as to develop proposals for creating effective value chains of a digital product for the consumer. As a result of the analysis, the following conclusions were formulated:

- for complex socio-economic systems to be able to respond to our time challenges in the context of digital economy transformation, it is necessary to introduce mechanisms that allow them to be transferred to a new qualitative level of development;

- introduction of an integrated approach to managing the development of complex socio-economic systems based on digital transformation of business will ensure the creation of effective value chains of a digital product for the consumer;

- the transition to data-centricity will allow us to provide the client with high-quality, timely service, as well as predict his behaviour, identify and shape his needs and preferences;

- digital transformation of a complex socio-economic system should completely eliminate the shortcomings of the existing irrational organizational structure, and, ideally, not improve it, but completely replace it;

- reengineering of the organizational structure must be carried out in the direction of its design on the basis of the formation of project or cross-teams that can combine business, IT sector, marketing, which will speed up the production cycle, reduce the time to market a product, reduce logistics costs and, ultimately, to form effective chains of formation and delivery of digital product value for the consumer;

- the concept of the development of complex socio-economic systems is based on the need to create an ecosystem, the basis of which should be a digital platform that provides for various models of interaction of ecosystem elements with the participation of services or applications of third parties in the product value chain for the client;

- an important condition for the effective ecosystem formation on a common basis (digital platform) is openness, which allows accepting new participants and, accordingly, reducing costs by attracting their resources.

\section{References}

1. A.V. Babkin, D.D. Burkaltseva, D.G. Kosten, Yu.N. Vorobev, Formation of the digital economy in Russia: essence, features, technical normalization, development problems, Scientific and technical statements of SPbSPU. Economic Sciences, 10 (3), 9-25 (2017)

2. V.G. Varnavskiy, Digital technologies and the world economy growth, Drucker bulletin, 3 (7), 73-80 (2015)

3. E.N. Veduta, Cross-sectoral-cross-sectoral balance: a mechanism for strategic planning of the economy (Moscow, 2016)

4. T.A. Gasanov, G.A. Gasanov, Digital economy as a new direction of economic theory, Regional problems of economic transformation, 6 (80), 4-10 (2017)

5. I.Yu. Grishin, R.R. Timirgaleeva, Digital economy: building and optimization of business processes, NovaInfo.Ru (Electronic magazine), 56-1 (2016) 
6. A.P. Dobrynin, K.Yu. Chernykh, V.P. Kupriyanovsky, P.V. Kupriyanovsky, S.A. Sinyagov, Digital economy - various ways to effectively apply technologies (bim, plm, cad, iot, smart city, big data and others), International journal of open information technologies, 4 (1), 4-11 (2016)

7. V.V. Klochkov, The influence of digital economy technologies on the industrial sector, Drucker Bulletin, 2, 59-67 (2018)

8. S.V. Makrushin, Digital economy: transformation of technologies into a new economic order. Makrushin, Property relations in the Russian Federation, 2 (197), 10-18 (2018)

9. B. Panshin, Digital economy: features and development trends, Science and innovations, 11 (2016)

10. E.V. Popov, Ekonotronika, Economy of the region, 14 (1), 13-28 (2018)

11. I.V. Sudarushkina, N.A. Stefanova, Digital economy, Azimuth of scientific research: economics and management, 6, 1 (18), 182-184 (2017)

12. R.R. Timirgaleeva, I.Yu. Grishin, V.V. Korotitskaya, Organization of business processes of tourist and recreational activities based on digital economy technologies, NovaInfo.Ru (Electronic magazine), 88 (2018)

13. R.R. Timirgaleeva, I.Yu. Grishin, Information and logistics support of the management process of complex organizational and economic systems (Simferopol, 2013)

14. G.N. Chernukhina, Modern management technologies in the digital economy, Bulletin of the Academy, 4, 24-28 (2017)

15. L. Wang, T. Kjellberg, Secure Information Model for Data Marketplaces enabling Global Distributed Manufacturing, 26 $6^{\text {th }}$ CIRP DESIGN CONFERENCE, 360-365 (2016)

16. T.K. Sung, Industry 4.0: A Korea perspective, Technological forecasting and social change, 40-45 (2017)

17. M. Nour Adi, E. Turnbull, B.H. Jiankun, A New Threat Intelligence Scheme for Safeguarding Industry 4.0 Systems, IEEE ACCESS, 6, 910-924 (2018)

18. F.Z. Qian, W. Du Wenli, Fundamental Theories and Key Technologies for Smart and Optimal Manufacturing in the Process Industry, Engineering, 3, 154-160 (2017)

19. P. Marcon, F. Zezulka, I. Vesely, Z. Szabo, Z. Roubal, O. Sajdl, E. Gescheidtova, P. Dohnal, Communication Technology for Industry 4.0, Progress in electromagnetics research symposium, 1694-1697 (2017)

20. R.R. Timirgaleeva, I.Yu. Grishin, The concept of formation of the ecosystem of the digital economy of the region, Increasing the competitiveness of socio-economic systems in the context of cross-border cooperation of regions. VI All-Russian scientific and practical conference with international participation, 93-95 (2019)

21. R.R. Timirgaleeva, I.Yu. Grishin, E.B. Babayan, V.V. Korotitskaya, Target model for the development of the digital ecosystem of the region, Natural and humanitarian research, 21 (3), 135-144 (2018) 